\title{
Constraints in the design of activities focusing on Emotion Recognition for children with ASD using robotic tools*
}

\author{
Sandra C. Costa, Filomena O. Soares, Member, IEEE; Ana P. Pereira and Fátima Moreira
}

\begin{abstract}
Robótica-Autismo project, presented in this paper, aims to identify the main aspects to be considered when working with robots and children with ASD (Autism Spectrum Disorders). Several constraints are identified such as the type of robot, the type of skills that should be developed, the criteria of inclusion and exclusion in the target group, which proceedings should be followed during the sessions and how to analyze the obtained results. In the end, a well-established methodology is achieved in order to accomplish the goal of using a robot as a mediator between children with ASD and other human partners.
\end{abstract}

\section{INTRODUCTION}

Autistic Spectrum Disorders (ASD) typically manifests during the first three years of life and they can be defined as a global development disorder. Each individual has particular abilities and disabilities, implying the necessity for dedicated intervention programs, based on the educational plan $[1,2]$.

On the basis of ASD diagnosis three basic behaviour modifications are considered: qualitative changes in social interactions, resulting in the pursuit of social isolation, qualitative changes in verbal and non-verbal communication abilities, namely: changes or absence of oral language, or echolalia, and a reduced, repetitive and stereotypical repertoire of activities and interests (called stereotypies) [3].

Specific methodologies have been used with children with ASD due to an earlier identification of the problem and early intensive intervention may result in substantially enhanced outcomes [4]. Applied behaviour analysis, the TEACCH method, developmental models, speech and language therapy, social skills instruction, occupational therapy and sensory integration therapy are some of the intervention approaches to improve communication [4-6] and train social skills $[7,8]$.

In the last few years, several projects were devoted to use robotics to improve certain skills in children with ASD namely self-initiated interactions [9, 10], turn-taking [11],

* This work was supported in part by the Portuguese Foundation for Science and Technology under the Project Contract FCT RIPD/ADA/109407/2009 and the scholarship SFRH/BD/71600/2010.

Costa, S., (corresponding author phone: +351253510190; fax: +351253510189; email: scosta@dei.uminho.pt) is with the Industrial Electronics Department, University of Minho, Guimarães, Portugal.

Soares, F. O. is with the Industrial Electronics Department, University of Minho, Guimarães, Portugal.

Pereira, A. P. is with the Institute on Children Studies, University of Minho, Braga, Portugal.

Moreira, F. is with the APPACDM (an association for mental disable people, in Portuguese Associação de Pais e Amigos do Cidadão com Deficiência Mental), Braga, Portugal. imitation [10-14], emotion recognition [12, 14-17], joint attention [12-13,18, 19], and triadic interactions [12, 20-23].

Besides these considerations, attention has been given to the type and form of robots used in ASD research. Some robots are humanoids $[9,12-14,17,19,21]$, while others are small, mobile, and car-like - non-humanoids configurations $[9,11,20]$. Each of these robot types has its advantages and disadvantages in working with children with ASD [24]; for instance, if the robot is an android, it may have a high potential for competences transfer but it can be the least engaging to children with ASD. A mascot retains the humanoid form, but has an abstract or cartoonish look. Mascot-like shapes may be more appealing than androids, but generalization could be more difficult to accomplish. A humanoid shape robot may have many visibly mechanical parts. Children with ASD may focus on these robots, mainly because they are more interested in the mechanical parts rather than in the robot/activity itself. Some robots look like small animals and they produce strong intense interactions, but they cannot replicate human-human interactions. Finally, non-humanoid mobile robots do not match any specific living form, being unsuccessful to imitate human-human interactions; however they can proficiently do certain tasks.

Project AURORA (AUtonomous RObotic platform as a remedial tool for children with Autism) [25] has been working for several years on the use of robotic systems applied to children with ASD. This investigation started with Labo-1, a mobile robot which can play games of tag with the children, forcing them to alternate between engaging and avoiding the robot [11]. Next step of the research was a humanoid robot, called Robota [10] which was used to elicit imitation games, using the legs, arms, and the head. It tested the reaction of low-functioning children with ASD to different human features of the robot and evaluated the extent to which low-functioning children with ASD are able to distinguish between perceptions being the result of their own actions from perceptions that are the result of the actions of others. From this study, they concluded that robots interacting with children with ASD should avoid the details and complexity of a human while still holding to the humanoid form. They subsequently designed the robot KASPAR to fit the design criteria [19]. KASPAR is an autonomous robot in call-and-response games, where its goal is to imitate the human partner. The researchers show that the use of KASPAR, not only can demonstrate some important interaction competencies, but also show a level of direct engagement where children appear to generalize behaviours at least to the other people in the testing room. 
In other line of investigation, with the Keepon robot, operators remotely direct its gaze toward the child or towards an object to establish joint attention [13]. When the child looks or points at the same object that Keepon is focused on, Keepon bounces to show its excitement, encouraging the child to keep on interacting. The authors affirm that simple robots with minimal expressiveness can smooth natural exchanges of mental states in children with ASD.

The IROMEC project (Interactive Robotic Social Mediators as Companions) [26] takes into account the needs to play of children, focusing its educational and therapeutic goals on reducing children's limitations by taking advantage of the skills they already have. The IROMEC play scenarios cover different goals in five different developmental areas (sensory, communicational and interaction, motor, cognitive and social, and emotional). The researchers conclude that IROMEC as a programmable system (defined as play scenarios) can provide several stimuli to promote the interaction with the child in different ways [26]. In addition to these studies, the research teams in $[12,14-17,27-30]$ also explore the use of robots to enhance of emotion recognition.

Under a partnership between University of Minho and APPACDM (Associação de Pais e Amigos do Cidadão com Deficiência Mental, an association for mentally disabled people), a research study [31-33] named Robótica-Autismo Project [31], was undertaken with the aim of using robots to improve the social life of children and adolescents with ASD, in particular to promote their social interaction and communication skills. The first study of this project [31-32] had the participation of adolescents with ASD and mental disability, where a Lego Mindstorms robot with different embodiments was used. Two boys with ASD and mental disability participated in this study. Caregivers, therapists and researchers previously discussed and planned in detail each experiments taking into account the characteristics of the adolescent. The conclusions resulting from this study [31-33] enabled to verify the adequacy of employing this technology to improve the social life, particularly social interaction, of people with ASD. Summarizing, the guiding principles of Robótica-Autismo project are: Skill Transfer, Triadic Relationship and the use of robots as a Complementary Intervention (Fig.1).

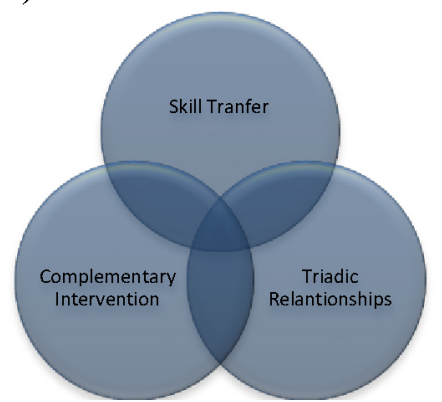

Fig. 1 - Main three guiding principles of the Project

Transferring skills is an important component that has to be developed with children with ASD [23]. The goal is that a developed and acquired skill in a known environment, should be executed in other contexts, for instance, in daily life tasks. Another important aspect to be considered is triadic relationships. We believe that it is especially important that the child does not interact only with the robot but that he/she uses it as a mediator to interact with other people. Thus, the robot can be used as a complementary intervention to children with ASD, to improve the reduced abilities previously discussed.

Under the Robótica-Autismo Project, several activities with children with ASD are being developed, where the robot plays one of the main roles. These activities were built with lacking skills in mind: Self-Initiated Instructions, TurnTaking Activities, Imitation, Joint Attention and Emotion Recognition. Some of the activities may have more than one category associated to them. It is well known that children with ASD, even with the same level of severity, are quite different. So, one activity may not be appropriate for one child, even if it produces excellent results with other children. For that reason, every activity was built with several levels to be adapted to every child. In the end, we should have a set of activities to develop several competences with children with ASD, aged from 7 and 12 years old. In this paper, special attention is devoted to Emotion Recognition.

The methodology to be applied, the partnerships, target group and the robot are presented in the next sections. The most important parameters of the activities to integrate in the robot are highlighted, as well as how the results of these activities will be analyzed. The implementation is presented and discussed and the paper ends with final comments and the future steps on the project.

\section{Methodology}

In this section, the partnership, the target group, the robot as well as the relevant parameters of the activities are detailed. Also, it is presented how the results are analyzed.

\section{A. Partnership}

One of the main concerns when establishing the main guiding principles of the methodology are where and with whom, we want to test our scenarios. The first step was to contact the Portuguese Ministry of Education to know how many children with ASD and how many ASD educational structured units exist in Portugal. These units are specialized rooms on public school based systems, where children with ASD are integrated and accompanied by professionals. Table 1 summarizes these numbers [35].

It is important to mention that the numbers presented in Table 1 consider are only the children attending public schools. Before 6 years old, these children attend other schools that are not considered by the Ministry of Education. It is also important to mention that children are normally diagnosed by specialized clinicians.

Table 1 - Number of structured units of ASD and Children with ASD in Portugal [35]

\begin{tabular}{|c|c|c|}
\hline & $\begin{array}{c}\text { ASD Structured } \\
\text { units }\end{array}$ & $\begin{array}{c}\text { Children with } \\
\text { ASD }\end{array}$ \\
\hline $\mathbf{2 0 0 9 / 2 0 1 0}$ & 187 & 795 \\
\hline $\mathbf{2 0 1 0} / \mathbf{2 0 1 1}$ & 231 & 1247 \\
\hline
\end{tabular}


Due to proximity reasons, 36 schools in the North of Portugal were invited to participate in the project. Six groups of schools accepted to participate, which provides a population of 64 children with ASD, aged from 3 and 12 years old. Collaboration protocols were formalized between the University and the partners. Besides these partnerships and due to project dissemination in the media, several professionals, associations of parents of children with ASD and specialized institutions demonstrated their interest in collaborating with Robótica-Autismo Project. Thus, we have more than 100 children with ASD available.

\section{B. Target Group}

The criteria for inclusion in the sample are the following: ages between 7 and 12 years old, children with ASD (with a diagnosis of a mild level of severity), acceptance of parents, and the children must also be attending a structured unit of autism. Children with mental impairments are considered as exclusion criteria from the sample. These criteria were considered to validate the results on the use of the robot in promoting skills in children with ASD. Therefore, the experimental activities were designed for this specific group children with ASD. The sample group for this study is then divided into three different groups:4 children in the Test Group, 20 children in the Experimental Group, 20 subjects in the Control Group. The experiments with the Test Group have the goal to find and correct technical failures from the software or hardware, while the elements in the Experimental and the Control group perform the experiment respectively with or without the robot.

The average duration of the session is previously known thanks to the Test Group. Nevertheless, this time is adapted to each child with ASD, due to the heterogeneity in the time of concentration in the task(most likely different for each child). The group age was selected between 7 and 12 years old, based on one of the stages of the cognitive development according to Piaget's theory [36]. This stage, called concrete operational stage, is characterized by the suitable use of logic. Children in this stage can only, however, solve problems that apply to concrete objects or events, and not abstract concepts or hypothetical tasks [36].

\section{Robot}

After a comparative study on the commercial robots available on the market, we decided to use Robokind Robot [37] - originally called Zeno. This robot has a humanoid form with a cartoonish appearance, which can be very useful for engaging a human being [324]. In the project, we called this robot ZECA (Zeno Engaging Children with ASD). ZECA has a expressive face, a walking body (with 31 degrees of freedom), software for speech recognition and speaking, several sensors (bump sensors on each foot, temperature, and torque/load, in the body and legs, among others) and his main characteristic is the skin made of a material called Frubber ${ }^{\mathrm{TM}}$, a biomimetic polymer, which can simulate facial expressions [37].

\section{Activities}

The steps to accomplish the design of the activities are the following: elaborate the activities concerning all the categories (Self-Initiated Instructions, Turn-Taking Activities, Imitation, Joint Attention and Emotion
Recognition), classify, revise (performed by the psychologists) and build the activities (programming and materials). Then, it is necessary to schedule sessions with the Test Group. These sessions have several goals: one of them is to elaborate a study to prove the safe use of the robot with children and that this robot is useful to attract their attention, engaging them in playful interactions. After that, it is important to execute the activities to see their relevance, what is the motivation and interest of the children towards the robot, but also to verify which characteristics are most appealing to the children. Moreover, it is necessary to identify what is the most appropriate duration of the sessions, deciding how to modify the level of the activity or the activity itself during the sessions. Finally, we are ready to schedule sessions with children with ASD, doing the activities and simultaneously evaluating the effectiveness of ZECA with this target group, which means, performing the technical evaluation of the robot, the usability assessment, and the evaluation of the possible effects that the interaction might have on users.

In this study, we consider as dependent variables the categories/activities and the interaction between peers. These variables are fundamental to see in what way the activities performed by ZECA can influence the intervention in ASD. As independent variables, we have the partner of game, the contexts/ environments and the age group. With these variables we want to affirm that children with ASD, using a robotic mediator, are able to transfer the acquired skills despite the partner of the game, the environment, or the age.

At this time, we have already worked on the first two steps, i.e., we have already organized the activities to implement and they are already validated by psychologists. As mentioned earlier, we want to address emotion recognition, using the robot to allow the child to recognize emotions in human beings. The following activities can be adapted to each child, with respect to levels of difficulty:

- Story Telling: the robot tells a story to the child,

- Recognize: the robot performs some facial expressions and gestures and the child tries to identify them.

\section{E. Analysis of the Activities}

To analyze the behaviours of the children, several indicators were specified to examine the progress of the child in the sessions/activities (Table 2).

Table 2 - Description and classification of the indicators

\begin{tabular}{|l|l|l|}
\hline Indicator (Abrv) & Description & Type \\
\hline Time_Interaction & $\begin{array}{l}\text { Time of Interaction (Eye } \\
\text { Contact and/or Manipulation) }\end{array}$ & Time \\
\hline N_Touch & $\begin{array}{l}\text { Number of times the child } \\
\text { touches the robot }\end{array}$ & Frequency \\
\hline N_Verbal_Robot & $\begin{array}{l}\text { Number of Verbal/vocal } \\
\text { behaviors directed to/about the } \\
\text { robot }\end{array}$ & Frequency \\
\hline N_Verbal_Person & $\begin{array}{l}\text { Number of Verbal/vocal } \\
\text { behaviors directed to/about the } \\
\text { third person }\end{array}$ & Frequency \\
\hline N_Stereotypies & $\begin{array}{l}\text { Number of stereotypies made } \\
\text { by the child (motor or oral) }\end{array}$ & Frequency \\
\hline Greeting & $\begin{array}{l}\text { The child greeted the } \\
\text { robot/researcher }\end{array}$ & (Y/E/N) \\
\hline Activity_Complete & The child managed to perform & (Y/E/N) \\
\hline
\end{tabular}




\begin{tabular}{|l|l|l|}
\hline & the activity completely & \\
\hline $\begin{array}{l}\text { Perform_Daily_Tas } \\
\text { k_Alone }\end{array}$ & $\begin{array}{l}\text { The child managed to perform } \\
\text { the daily task alone }\end{array}$ & (Y/E/N) \\
\hline
\end{tabular}

For these play scenarios, we have in total 8 indicators of three different types: Time, Frequency and $\mathrm{Y} / \mathrm{E} / \mathrm{N}$. This last one refers to $\mathrm{Y}$ - Yes, $\mathrm{E}$ - Emerging and $\mathrm{N}$ - No. When a behaviour is emerging, it means that the subject tried to accomplish the desirable performance but he could not yet do it completely. These indicators will be quantified when the videos are analyzed.

\section{$F$. Video Analysis}

All the sessions are recorded with a set of video cameras, which cover $360^{\circ}$ global vision of the room where the sessions are performed. The recording scheme, as well as the type of observational data representation, must be carefully chosen prior to video observation. There are several recording schemes: coding events, recording onset and offset times, recording timing patterns changes, coding intervals and recording cross-classifying events [38]. The onset and offset times for recording behavioural sequences were chosen.

This form of recording scheme was selected because, for most of the research questions, it is necessary information about time of the events. In this way, it is possible to report time-budget information and report different kinds of behaviours coordinated with time. To facilitate, it is useful that the codes are mutually exclusive and exhaustive because then offset times do not need to be recorded. In such cases, the offset of a code is implied by the onset of another mutually exhaustive code. So, with this recording scheme (Figure 2), it is possible to preserve a complete record of how the behaviour unfolds in time, recording the onset (and offset, when it is necessary) times for all codable events [38].

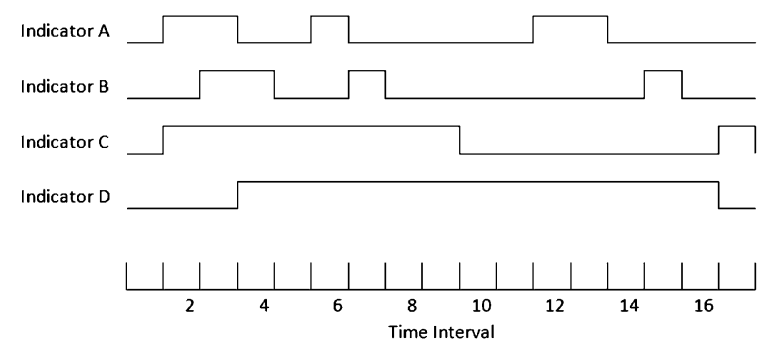

Fig. 2 - Example of the output produced by an event recorder

The use of coding events is advantageous, especially if we are concerned with the sequence of behaviours, not with the duration of the previous or next behaviour. So, coding events are also a recording scheme to be used [38].

After choosing the recording scheme, it is important to decide which observational data representation is going to be used. There are five forms of representing observational data discussed: event sequences, state sequences, timed-event sequences, interval sequences, and cross-classified events [38]. It is worth mentioning that depending on how data is recorded, we can extract different representations from the same data for different purposes. For this project, the data representation form is event sequences for coding events and events, state, time-event or interval sequences for recording onset and offset times. After a careful reading of the advantages and disadvantages of each one, we selected one representation to be used: time-event sequences. Time-event sequences allow events to occur and momentary and duration behaviours are indicated along with their onset and offset times. Once data is represented in this form, we can determine quite easily how often specific behavioural codes occur, or whether certain behavioural codes tend to follow (or precede) other codes in systematic ways. The flexibility of the timed-event format is very useful and codes can be defined for any number of behaviours, preserving onset and offset times. As mentioned before, event sequences are going to be used to represent observational data from events coded. Event sequences consist simply of codes for the events, ordered as they occur [38].

\section{IMPLEMENTATION}

In all the designed activities, six phases are common. These phase were created as a "conducting wire" throughout the proceeding, allowing then to validate research questions and to infer reliable conclusions.

\section{G. Phases}

The six phases defined are:

- Checking Phase: The developed activities are tested with children with ASD not included in the Experimental and Control Groups.

- Familiarization: The goal of this phase is the researcher to get acquainted to the child and to integrate her in the school environment. The researcher should perform one session with the robot, where the child can interact with the robot as he/she wishes.

- Pre-Test: The objective of this phase is to as certain which competences the children have. It is considered a performance task as the event is different from the activities carried out in the following phases and the robot is not yet present in the experiment. This phase has a duration of 10 minutes.

- Practice: The task is introduced in the child daily work. The Practice phase consists of two different activities (A and $B$ ) structured in the following way: $1^{\text {st }}$ session - activity A; $2^{\text {nd }}$ session- activity $B ; 3^{\text {rd }}$ session - activities $A+B$. A and B indicate activities that work on the same skill. Consequently, there are 3 sessions of 10 minutes.

- Re-Test: This phase is performed with a one week interval from the Practice phase; it lasts $10 \mathrm{~min}$. Re-Test phase has the same conditions as the Pre-Test phase and has the objective of evaluate the consistency of learning. That is, to evaluate if the child, after the interruption of the sessions, is able to successfully perform the task, i.e. whether he/she is able to respond to the initiative of the adult to interact.

- Skill Transfer: In the Skill Transfer phase, some changes of context/models of the experiment are made, to evaluate child's performance concerning to the ability to transpose his/her new capacities. There are different environments (classroom and playground) and also different models (with known and unknown game partners) to verify if the robot 
succeeded as a promoter to improve the child's social interactions and skills transfer. In this phase, 5 sessions of 10 minutes each are performed. As mentioned earlier, one of the main goals of this project is the transfer of competences. Several changes can be made in this phase: change of partners, change of materials or instructions, change of contexts, change of functional routine, and change of natural environment. In this study, besides the changes in partners and natural environments, we want to promote changes of contexts; for instance, if, in the experiment, a child learned the colours, in this phase he/she learns that there are other objects that have the same colour of the object considered in the activity.

\section{$H$. Structure of the activities}

In this section, the main educational objectives of the activities, as well as the associated research questions are detailed. The key algorithms are also presented.

\section{1)Main Objectives}

The main objectives of the research are:

- Elicit joint attention between the child and the adult;

- Use the robot to elicit interaction between the child and the third person in the experiment;

- Recognize if the child has the ability to understand another person's perspective.

\section{2) Research Questions}

There are three main research questions:

- In what way did the robot contribute to elicit interaction between the child and the third person in the experiment?

- Can the robot be used to promote the understanding of another person's perspective?

- Can the child identify an emotional state with the help of the robot?

In Figure 3, the emotions we want to work with the child are shown: happy, scared, sad, confused, angry and tired.

In the first level of the Telling Stories activity, the robot starts telling a story in which it is the main actor. The researcher asks some questions to the robot about the story. The stories have more than one ending, where the robot feels happy, sad, surprised, tired, among others. The researcher asks the child how the robot feels in the first level. In the second level of the activity, the story is told by another person, instead of the robot, and in the third level, who tells the story (robot or other person) is neutral in the end. The child has to say which emotional state have the one who is telling the story (maintain the same story in level 2). There are 13 small stories created for this purpose.

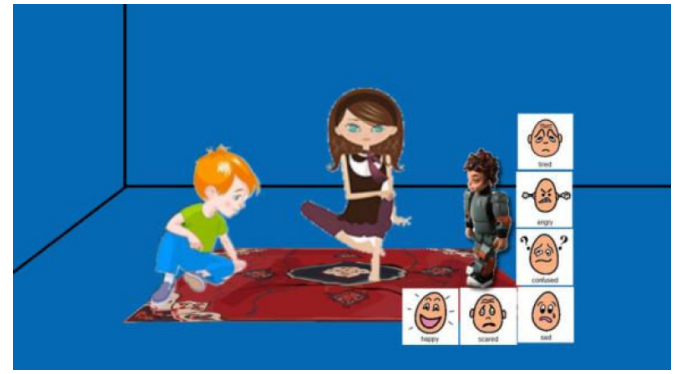

Fig. 3 - Scenario of the Recognition Activity

Concerning the Recognition activity, in the first level, the robot performs one facial expression, accompanied by a gesture. The researcher asks the child which expression the robot is performing and the child answers, choosing the corresponding card (with the photo of the robot performing the emotion). If the child answers correctly, the robot greets him. If not, the researcher asks him/her one more time. If he/she does not answer correctly, the robot gives the correct answer and continues to the next expression. The task ends when the time is up. The second level of this activity differs from the first one, because when the child answers, he/she is using cards with PECS (Picture Exchange Communication System) representing the emotion. In the third level, the child answers, choosing the respective card with a photo of a known person, performing the emotion and finally in the fourth level, the child answers verbally.

\section{FINAL COMMENTS}

The main constraints when designing activities involving the use of robotic tools with children with ASD were discussed. It is fundamental that the robot is appealing to the child, without scaring him/her, has a humanoid form so that the child can easily transfer the lacking competences directly connected to this spectrum. The proceedings during the sessions were detailed, as well as the methods for video analysis. The key goal of Robótica-Autismo project is to put the technology, in particular robotics, at the service of children with ASD, improving their daily life.

In future work, we want to test the algorithms using this methodology and to develop a set of activities that can be used to promote several capabilities in children with ASD. Special attention should be given to the emotional body language displayed by the robot in order for it to be socially accepted and generate empathy [39]. Hidden Markov Models or HAMMER Models will be discussed as methods to infer the intention of the child when interacting with the robot.

\section{ACKNOWLEDGMENT}

The authors are grateful to the Portuguese Foundation for Science and Technology, FCT - Fundação para a Ciência e a Tecnologia, for funding through the R\&D project reference RIPD/ADA/109407/2009 and the scholarship SFRH/BD/71600/2010. This work is also supported by a QREN initiative, from UE/FEDER (Fundo Europeu de Desenvolvimento Regional) funds through the "Programa Operacional Factores de Competitividade - COMPETE". 


\section{REFERENCES}

[1] E. Schopler, G. B. Mesibow, (Eds), (1987). Neurobiological issues in autism, en Current issues in autism (series). New York: Plenum Press

[2] C. Giellberg\& M. Coleman, (Eds) (1992). The biology of the autistic syndromes, 2nd ed.,Londres: Mackeith

[3] M. First, A. Frances \&H. Pincus, (2002). DSM-IV-TR - Handbook of differential diagnosis. Arlington: American Psychiatric Association

[4] National Research Council, Committee on Educational Interventions for Children with Autism.Educating Children With Autism. Lord C, McGee JP, eds. Washington, DC: National Academies Press; 2001

[5] H. Goldstein, Communication intervention for children with autism: a review of treatment efficacy. J Autism Dev Disord. 2002;32 :373 -396

[6] L. K. Koegel, Interventions to facilitate communication in autism. J Autism Dev Disord. 2000;30:383 -391

[7] J. D. Bregman, D. Zager, J. Gerdtz, Behavioral interventions. In: Volkmar FR, Paul R, Klin A, Cohen D, eds. Handbook of Autism and Pervasive Developmental Disorders. 3rd ed. Vol II. Hoboken NJ: John Wiley \& Sons; 2005:897 -924

[8] P. A. Lorimer, R. L. Simpson, B. S. Myle, et al, The use of social stories as a preventative behavioral intervention in a home setting with a child with autism. J Posit Behav Interv. 2002;4:53-60

[9] D.J. Feil-Seifer and M. Mataric. Robot-Assisted Therapy for Children with Autism Spectrum Disorders. Procs. Conf. on Interaction Design for Children: Children with Special Needs, Chicago, USA (2008).

[10] B. Robins, K. Dautenhahn, R. Te Boekhorst, and A. Billard, "Robotic Assistants in Therapy and Education of Children with Autism: Can a Small Humanoid Robot Help Encourage Social Interaction Skills?" Universal Access in the Information Society (Heidelberg), vol. 4, issue 2, pp. 105-120, Dec. 2005.

[11] K. Dautenhahn and I. Werry. Towards interactive robots in autism therapy: Background, motivation and challenges. Pragmatics \&Cognition, 12:1-35 (2004)

[12] A. Duquette, F. Michaud, H. Mercier, (2007), "Exploring the use of a mobile robot as an imitation agent with children with lowfunctioning autism," Autonomous Robots - Special Issue on Socially Assistive Robotics 24(2): 147-157. (pdf)

[13] H. Kozima, and C. Nakagawa. "Interactive robots as facilitators of children's social development." Mobile Robots towards New Applications, Edited by Aleksandar Lazinica, pp. 784, Germany, December 2006 (2005).

[14] G. Pioggia, R. Igliozzi, M. L. Sica, M. Ferro, F. Muratori, A. Ahluwalia, and D. De Rossi, "Exploring emotional and imitational android-based interactions in autistic spectrum disorders," Journal of CyberTherapy \& Rehabilitation, vol. 1, issue 1, Spring 2008, pp. 4961 .

[15] K. D. Atwood, "Recognition of Facial Expressions of Six Emotions by Children with Specific Language Impairment," BYU Departmentof Communications Disorders Master's Thesis, August 2006.

[16] M. Blow, K. Dautenhahn, A. Appleby, C. L. Nehaniv, and D. Lee, "The art of designing robot faces - dimensions for human-robot interaction," Human Robot Interaction, Salt Lake City, UT, 2006.

[17] G. Pioggia, R. Igliozzi, M. Ferro, A. Ahluwalia, F. Muratori, and D. De Rossi. An android for enhancing social skills and emotion recognition in people with autism. IEEE Trans. on Neural Systemsand Rehabilitation Engineering, 13(4): 507-15 (2005).

[18] P. De Silva, K. Tadano, A. Saito, S. Lambacher, and M. Higashi, "Therapeutic-assisted robot for children with autism," The 2009 IEEE/RSJ International Conference on Intelligent Robots and Systems, Oct. 11-15, 2009, St. Louis, USA.

[19] B. Robins, K. Dautenhahn, and J. Dubowski, "Does appearance matter in the interaction of children with autism with a humanoid robot?" Interaction Studies, vol. 7, no. 3, pp. 479-512, 2006

[20] B. Scassellati. Personal communication, Nov. 2008

[21] H. Kozima, C. Nakagawa, and Y. Yasuda. "Interactive robots for communication-care: a case-study in autism therapy." Procs. IEEE Int. Symp. on Robot and Human Interactive Communication (ROMAN05), Nashville, USA, (2005).
[22] B. Robins and K. Dautenhahn. "The Role of the Experimenter in HRI Research - a Case Study Evaluation of Children with Autism Interacting with a Robotic Toy." Procs. IEEE Int. Symp. on Robot and Human Interactive Communication (RO-MANO6), Hatfield, $\mathrm{UK}(2006)$.

[23] M. Colton, D. Ricks, M. Goodrich, B. Dariush, K. Fujimura, and M Fukiki, "Toward therapist-in-the-loop assistive robotics for children with autism and specific language impairment," AISB Symposium: New Frontiers in Human-Robot Interaction (2009).

[24] D. Ricks and M. Colton, Trends and Considerations in Robot-Assisted Autism Therapy, 2010 IEEE International Conference on Robotics and Automation (ICRA), 3-7 May 2010, Anchorage, AK, 4354 - 4359

[25] www.aurora-project.com (accessed on March 2012)

[26] E. Ferrari,B. Robins, K. Dautenhahn, (2009), Therapeutic and educational objectives in Robot Assisted Play for children with autism, The 18th IEEE International Symposium on Robot and Human Interactive Communication Toyama, Japan, Sept. 27-Oct. 2, 2009

[27] G. Pioggia, A. Ahluwalia, F. Carpi, A. Marchetti, M. Ferro, W. Rocchia, and D. De Rossi, "FACE: Facial automaton for conveying emotions," Appl. Bionics Biomech., vol. 1, no. 2, pp. 91-100, 2004.

[28] G. Pioggia, R. Igliozzi, M. Ferro, A. Ahluwalia, F. Muratori, D. De Rossi, "An android for enhancing social skills and emotion recognition in people with autism," Neural Systems and Rehabilitation Engineering, IEEE Transactions on, vol.13, no.4, pp.507-515, Dec. 2005

[29] D. Feil-Seifer, M. Mataric, "Automated detection and classification of positive vs. negative robot interactions with children with autism using distance-based features", HRI '11 Proceedings of the 6th international conference on Human-robot interactio, Lausanne, Switzerland, 2011

[30] C. Breazeal, Rodney Brooks, "Robot Emotions: A Functional Perspective", In J. Fellous (ed.), Who Needs Emotions. Oxford University Press, 2004

[31] S. Costa, J. Resende, F. Soares, M. J. Ferreira, C. Santos, F. Moreira Applications of Simple Robots to Encourage Social Receptiveness of Adolescents with Autism, The 31st Annual International IEEE EMBS Conference, Sept. 2-6, 2009, Hilton Minneapolis, MN, USA

[32] S. Costa,J. Resende, F. Soares, M. J. Ferreira, C. Santos, F. Moreira, Promoting interaction amongst autistic adolescents using robots, The 32st Annual International IEEE EMBS Conference, Aug. 31 2010Sept. 4 2010, Buenos Aires, Argentina

[33] S. Costa, F. Soares, C. Santos, M. J. Ferreira, F. Moreira, A. P. Pereira and F. Cunha, An approach to promote social and communication behaviors in children with Autism Spectrum Disorders: Robot based intervention, Ro-Man 2011, 20th IEEE International Symposium on Robot and Human Interactive Communication, August 2011, Atlanta, Georgia.

[34] http://robotica-autismo.com/ (Consulted in January 2012)

[35] http://www.gepe.min-edu.pt/np4/?newsId=520\&fileName=GEPE Setembro.pdf (Consulted in January 2012)

[36] H. Ginsburg and S. Opper (1979), Piaget's Theory of Intellectual Development, Prentice Hall, ISBN 0-13-675140-7, p. 152.

[37] http://hansonrobokind.com/ (Consulted in January 2012)

[38] R. Bakemam and J. M. Gottman (1997), "Observing Interaction - An Introduction to Sequential Analysis", 2nd Ed., Cambrigde University Press, ISBN-10: 0521574277

[39] A. Beck, L. Canamero and K. Bard, Towards an Affect Space for robots to display emotional body language, Procs of the 19th IEEE Int Symposium on Robot and Human Interactive Communication, Viareggio, Italy, September 2010 